\title{
AKSESIBILITAS STASIUN KERETA REL LISTRIK COMMUTER LINE BERDASARKAN PERSEPSI WANITA
}

\author{
Radella Adelia Jayanti \\ Program Studi Teknik Sipil \\ Fakultas Teknik \\ Universitas Katolik Parahyangan \\ Jln. Ciumbuleuit No. 94 \\ Bandung 40141 \\ Tlp. (022) 4205090 \\ radellajayanti24@gmail.com
}

\author{
Tri Basuki Joewono \\ Program Studi Teknik Sipil \\ Fakultas Teknik \\ Universitas Katolik Parahyangan \\ Jln. Ciumbuleuit No. 94 \\ Bandung 40141 \\ Tlp. (022) 4205090 \\ vftribas@unpar.ac.id
}

\author{
Muhamad Rizki \\ Program Studi Teknik Sipil \\ Fakultas Teknik Sipil dan \\ Perencanaan \\ Institut Teknologi Nasional \\ Jln. PH Mustofa No. 23 \\ Bandung 40124 \\ Tlp. (022) 7272215
}

Muhamadrizki1404@itenas.ac.id

\begin{abstract}
Transportation facilities are said to be good for all gender groups if they provide satisfactory services to all users, including women, who tend to use public transportation regularly. This study aims to analyze the effect of women's perceptions on the accessibility attributes of stations based on the feeder mode to the station and the frequency of negative experiences on the level of accessibility of the Commuter Line Electric Rail Station as a whole. The data used in this study are primary data from the distribution of online questionnaires to women, Electric Rail Commuter Line users. This study shows that the clarity of information boards and directions for disembarking passengers, as well as the quality of the lighting for passengers to get off, tend to influence the overall level of station accessibility. The negative experience, in the form of getting lost on the way to the station, is also a variable that affects the assessment of the level of station accessibility in the private or passenger vehicle model as a feeder mode.
\end{abstract}

Keywords: station; Commuter Line; perception of women; feeder mode; negative experiences.

\begin{abstract}
Abstrak
Fasilitas transportasi dikatakan baik bagi seluruh kelompok gender jika memberikan layanan yang memuaskan bagi semua pengguna, termasuk wanita, yang cenderung menggunakan transportasi umum secara rutin. Studi ini bertujuan untuk menganalisis pengaruh persepsi wanita terhadap atribut aksesibilitas stasiun berdasarkan moda pengumpan menuju stasiun dan frekuensi pengalaman negatif terhadap tingkat aksesibilitas stasiun Kereta Rel Listrik Commuter Line secara keseluruhan. Data yang digunakan pada studi ini merupakan data primer hasil penyebaran kuesioner secara daring kepada wanita, pengguna KRL Commuter Line. Studi ini menunjukkan bahwa kejelasan papan informasi dan petunjuk arah untuk turun penumpang, serta kualitas pencahayaan tempat turun penumpang cenderung memengaruhi penilaian tingkat aksesibilitas stasiun secara keseluruhan. Pengalaman negatif, berupa tersesat dalam perjalanan menuju stasiun, juga merupakan variabel yang memengaruhi penilaian tingkat aksesibilitas stasiun pada model kendaraan pribadi atau penumpang sebagai moda pengumpan.
\end{abstract}

Kata-kata kunci: stasiun; Commuter Line; persepsi wanita; moda pengumpan; pengalaman negatif.

\section{PENDAHULUAN}

Aksesibilitas merupakan ukuran kemudahan suatu tata guna lahan dalam kaitannya antara satu sama lain dan kemudahan lokasi tersebut dicapai melalui sistem jaringan transportasi (Black, 1981). Tingkat kemudahan atau tingkat kesulitan untuk mencapai lokasi tersebut, melalui sistem jaringan transportasi, merupakan hal yang subjektif, kualitatif, dan relatif (Tamin, 2000). Karakteristik individu juga memengaruhi akses seseorang ke moda 
transportasi, dalam hal kebutuhan, peluang, dan kemampuan, yang menetapkan kendala temporal-spasial, misalnya usia dan kondisi fisik (Van Wee dan Geurs, 2011).

Akses transportasi umum di Provinsi DKI Jakarta, sebagai kawasan megapolitan yang dikelilingi oleh kota-kota besar, dinilai masih kurang integratif (Hikam, 2019). Padahal aktivitas di Jakarta ini merupakan 1 kesatuan dengan sistem kegiatan dalam kawasan aglomerasi Jakarta, Bogor, Depok, Tangerang, dan Bekasi, atau disingkat Jabodetabek (Lusiani dan Chandra, 2018).

Dalam melakukan kegiatan transportasi, sarana transportasi darat andalan masyarakat Jabodetabek adalah kereta rel listrik, yang dikenal dengan nama KRL Commuter Line Jabodetabek (Sukwadi dan Teofilus, 2015). Berdasarkan data hingga Juni 2018, jumlah ratarata pengguna KRL per hari mencapai 1.001 .438 orang pada hari kerja, dengan jumlah pengguna per hari terbanyak mencapai 1.154.080 (Saleh, 2019).

Dalam operasinya KRL Commuter Line memiliki stasiun, sebagai tempat untuk menaikkan dan menurunkan penumpang yang menggunakan jasa transportasi kereta api (Intari et al., 2017), dengan jumlah 80 stasiun untuk 6 jalur. Salah satu aspek penting yang memengaruhi kepuasan penumpang terhadap keseluruhan perjalanan menggunakan kereta api adalah aksesibilitas stasiun. Jarak antara satu stasiun dengan stasiun lainnya relatif jauh, padahal perjalanan menuju ke stasiun merupakan bagian penting pada perjalanan menggunakan kereta, yang perlu diperhitungkan dalam upaya meningkatkan penggunaan kereta api (Givoni dan Rietveld, 2007).

Kebutuhan aksesibilitas terhadap suatu moda transportasi bagi setiap kelompok masyarakat berbeda, termasuk antara laki-laki dan perempuan. Ketidaksetaraan gender ini masih menjadi suatu masalah yang butuh perhatian agar kebutuhan perempuan dalam melakukan perjalanan dapat terakomodasi secara responsif gender. Selain itu, transportasi dikatakan baik bagi seluruh kelompok gender bila dinilai baik oleh perempuan maupun lakilaki (Maffi et al., 2015).

Berdasarkan latar belakang tersebut, tujuan penelitian ini adalah untuk menganalisis pengaruh persepsi perempuan mengenai atribut aksesibilitas dan frekuensi pengalaman negatif terhadap tingkat aksesibilitas stasiun KRL Commuter Line secara keseluruhan, berdasarkan moda pengumpan atau moda terakhir yang digunakan dalam perjalanan menuju stasiun asal atau stasiun tempat memulai perjalanan menggunakan KRL Commuter Line. Pemahaman mengenai akses suatu transportasi umum berdasarkan penilaian perempuan tersebut dapat menjadi dasar dalam mewujudkan transportasi umum yang dapat memenuhi kebutuhan seluruh penggunanya.

\section{PENGUMPULAN DATA}

Kuesioner dirumuskan berdasarkan kajian literatur tentang aksesibilitas angkutan umum. Kuesioner tersebut terbagi menjadi 5 bagian, yang meliputi pembahasan karakteristik demografi, karakteristik perjalanan, persepsi mengenai atribut aksesibilitas stasiun, penilaian 
terhadap tingkat aksesibilitas stasiun secara keseluruhan, dan frekuensi pengalaman negatif dalam perjalanan menuju stasiun.

Terdapat 3 jenis pertanyaan dalam kuesioner, yaitu pertanyaan dengan pilihan terbatas sesuai dengan alternatif yang disediakan, pertanyaan dengan pilihan terbuka untuk menyatakan jumlah, dan pertanyaan dengan skala likert. Dalam pertanyaan dengan pilihan berbentuk skala likert, responden menentukan tingkat persetujuan terhadap masing-masing pertanyaan dengan memilih 1 dari 5 pilihan yang tersedia, dalam bentuk pertanyaan positif yang diberi skor 5, 4, 3, 2, 1. Pada bagian persepsi mengenai atribut aksesibilitas stasiun, pertanyaan yang diajukan hanya berdasarkan moda terakhir yang digunakan oleh responden dalam perjalanan menuju stasiun, sehingga dapat diketahui variabel-variabel atribut aksesibilitas yang berpengaruh secara signifikan terhadap penilaian tingkat aksesibilitas stasiun dengan mengacu pada moda transportasi secara spesifik.

Setelah kuesioner dirumuskan, dilakukan pengujian pendahuluan kuesioner kepada 30 orang. Selanjutnya kuesioner disempurnakan dan dilakukan perencanaan penyebaran untuk mendapatkan data primer. Jumlah populasi dalam penelitian ini adalah jumlah penumpang KRL Commuter Line per hari terbanyak, yaitu sebesar 1.154.080 yang terjadi pada tahun 2019 (Saleh, 2019). Dengan tingkat kepercayaan 95\%, ukuran sampel ditentukan sebanyak 400 responden berdasarkan rumus Yamane (Israel, 2009), seperti ditunjukkan pada Persamaan 1.

$$
n=\frac{N}{1+N \cdot e^{2}}
$$

dengan:

$\mathrm{n}$ = ukuran sampel;

$\mathrm{N}=$ jumlah populasi;

$\mathrm{e}=$ tingkat keterandalan .

Survei dilakukan secara daring dengan membagikan link kuesioner online di media sosial pada bulan April 2020. Target responden kuesioner adalah wanita pengguna KRL Commuter Line di Jabodetabek. Dari survei yang dilakukan, terkumpul 532 data. Namun setelah dilakukan review terhadap data tersebut, hanya 441 set data yang dianalisis.

\section{ANALISIS}

\section{Karakteristik Demografi dan Rumah Tangga}

Data pada Tabel 1 menunjukkan bahwa mayoritas responden berusia (17-25) tahun $(81,4 \%)$, dengan pekerjaan sebagai pelajar atau mahasiswa (60,1\%). Sebagian besar pendapatan responden berkisar antara 1 sampai 3 juta rupiah $(29,9 \%)$, kurang dari 1 juta rupiah $(25,4 \%)$, dan antara 3 sampai 6 juta rupiah (25,2\%). Proporsi paling banyak untuk tipe rumah tangga responden adalah tinggal dengan orang tua, yaitu sebesar $79,8 \%$. 
Tabel 1 Karakteristik Demografi dan Rumah Tangga $(n=441)$

\begin{tabular}{|c|c|c|}
\hline \multicolumn{2}{|c|}{ Karakteristik Responden } & Proporsi $(\%)$ \\
\hline \multirow{6}{*}{ Usia } & $<17$ tahun & 1,1 \\
\hline & $17-25$ tahun & 81,4 \\
\hline & 26-35 tahun & 12,7 \\
\hline & $36-45$ tahun & 2,7 \\
\hline & $45-55$ tahun & 1,6 \\
\hline & $>55$ tahun & 0,5 \\
\hline \multirow{8}{*}{ Pekerjaan } & Pelajar/Mahasiswa & 60,1 \\
\hline & Pegawai Negeri/TNI/Polri & 3,6 \\
\hline & Pegawai Swasta/BUMN & 30,6 \\
\hline & Wirausaha & 0,5 \\
\hline & Dosen/Guru/Dokter & 1,6 \\
\hline & Ibu Rumah Tangga & 0,9 \\
\hline & Pensiunan/Tidak Bekerja & 0,7 \\
\hline & Lainnya & 2 \\
\hline \multirow{8}{*}{ Pendapatan } & $<\mathrm{Rp} 1.000 .000$ & 25,4 \\
\hline & Rp1.000.001-Rp3.000.000 & 29,9 \\
\hline & Rp3.000.001-Rp6.000.000 & 25,2 \\
\hline & Rp6.000.001-Rp9.000.000 & 11,3 \\
\hline & Rp9.000.001-Rp12.000.000 & 3,2 \\
\hline & Rp12.000.001-Rp17.000.000 & 2,5 \\
\hline & Rp17.000.001-Rp22.000.000 & 0,9 \\
\hline & $>\mathrm{Rp} 22.000 .000$ & 1,6 \\
\hline \multicolumn{2}{|c|}{ Karakteristik Rumah Tangga } & Proporsi (\%) \\
\hline \multirow{7}{*}{ Tipe Rumah Tangga } & Sendiri & 6,8 \\
\hline & Sendiri dengan anak & 0,5 \\
\hline & Pasangan tanpa anak & 2,9 \\
\hline & Pasangan dengan anak & 6,6 \\
\hline & Tinggal dengan orang tua & 79,8 \\
\hline & Pasangan yang tinggal dengan orang tua & 1,1 \\
\hline & Lainnya & 2,3 \\
\hline
\end{tabular}

\section{Karakteristik Perjalanan}

Data mengenai karakteristik perjalanan responden disajikan pada Tabel 2. Umumnya responden memiliki tujuan perjalanan menggunakan KRL Commuter Line untuk sekolah atau kuliah, yaitu sebesar 44,9\%, dan untuk bekerja, yaitu sebesar 35,6\%. Dalam perjalanan menuju stasiun asal, mayoritas responden memulai perjalanan menggunakan KRL Commuter Line dari Commuter Line Red Line (rute Bogor/Depok-Manggarai-Jakarta Kota), dengan proporsi sebesar $34,2 \%$.

Mayoritas wanita pengguna KRL Commuter Line hanya menggunakan 1 moda transportasi dalam perjalanan menuju stasiun asal, dengan proporsi lebih dari setengah responden $(74,6 \%)$ dan dilanjutkan dengan menggunakan 2 moda transportasi $(21,1 \%)$. Dari hasil tersebut dapat dikatakan bahwa responden tidak melakukan peralihan moda transportasi dalam perjalanan menuju stasiun. Jarak tempuh dari tempat tinggal responden menuju stasiun asal kebanyakan adalah (1-5) km, sebanyak 44,9\%, dilanjutkan dengan jarak kedua terbesar adalah $500 \mathrm{~m}$ hingga $1 \mathrm{~km}$, sebanyak 25,6\%. Hal ini menunjukkan bahwa tempat tinggal responden menuju stasiun tidak terlampau jauh dari lokasi-lokasi stasiun. 
Tabel 2 Karakteristik Perjalanan $(n=441)$

\begin{tabular}{|c|c|c|}
\hline Karakteristik Perjalanan & & Proporsi (\%) \\
\hline \multirow{6}{*}{ Tujuan Perjalanan } & Bekerja & 35,6 \\
\hline & Berbelanja & 0,9 \\
\hline & Rekreasi & 6,1 \\
\hline & Sekolah/Kuliah & 44,9 \\
\hline & Bertemu teman/keluarga & 9,5 \\
\hline & Lainnya & 2,9 \\
\hline \multirow{5}{*}{ Jalur/line Awal } & $\begin{array}{l}\text { Bogor/Depok-Manggarai-Jakarta Kota (Red } \\
\text { Line/Merah) }\end{array}$ & 34,2 \\
\hline & $\begin{array}{l}\text { Rangkasbitung/Maja/Parung Panjang/Serpong- } \\
\text { Tanah Abang (Green Line/Hijau) }\end{array}$ & 28,6 \\
\hline & Tangerang-Duri (Brown Line/Cokelat) & 5,4 \\
\hline & $\begin{array}{l}\text { Bogor/Depok-Tanah Abang-Pasar Senen-- } \\
\text { Jatinegara (Loop Line/Yellow Line/Kuning) }\end{array}$ & 11,3 \\
\hline & $\begin{array}{l}\text { Bekasi-Jatinegara-Manggarai-Jakarta Kota } \\
\text { (Blue Line/Biru) }\end{array}$ & 20,4 \\
\hline \multirow{4}{*}{$\begin{array}{l}\text { Jumlah moda transportasi yang } \\
\text { biasa digunakan menuju stasiun } \\
\text { asal dalam satu kali perjalanan }\end{array}$} & 1 moda & 74,6 \\
\hline & 2 moda & 21,1 \\
\hline & 3 moda & 3,9 \\
\hline & 4 moda & 0,5 \\
\hline \multirow{5}{*}{ Jarak tempuh menuju stasiun asal } & $<500 \mathrm{~m}$ & 9,5 \\
\hline & $500 \mathrm{~m}-1 \mathrm{~km}$ & 25,6 \\
\hline & $1-5 \mathrm{~km}$ & 44,9 \\
\hline & $5-10 \mathrm{~km}$ & 15,4 \\
\hline & $>10 \mathrm{~km}$ & 4,5 \\
\hline \multirow{6}{*}{$\begin{array}{l}\text { Waktu tempuh menuju stasiun } \\
\text { asal }\end{array}$} & $<5$ menit & 9,5 \\
\hline & 5-15 menit & 55,6 \\
\hline & $15-30$ menit & 27,2 \\
\hline & $30-45$ menit & 5,7 \\
\hline & $45-60$ menit & 1,6 \\
\hline & $>60$ menit & 0,5 \\
\hline
\end{tabular}

Untuk waktu tempuh dari tempat tinggal responden menuju stasiun, mayoritas ditempuh dengan waktu (5-15) menit, dengan proporsi sebesar 55,6\%. Biaya rata-rata menuju stasiun asal, yang meliputi biaya parkir yang digunakan, adalah antara Rp5.001 hingga Rp15.000, yang merupakan proporsi tertinggi, yaitu sebesar $44,9 \%$ terhadap total responden.

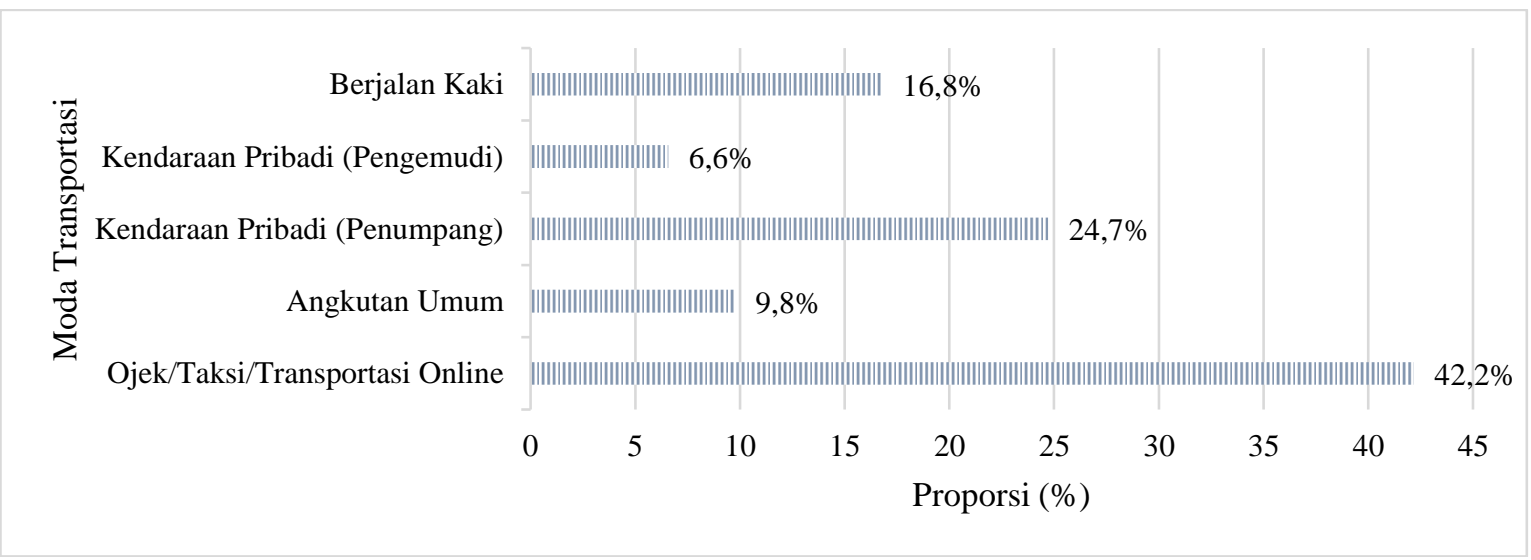

Gambar 1 Moda Terakhir yang Digunakan Menuju Stasiun Asal ( $\mathrm{n}=441)$ 
Proporsi moda terakhir yang digunakan responden dalam perjalanan menuju stasiun asal disajikan pada Gambar 1. Hampir setengah dari seluruh responden mencapai stasiun asal menggunakan ojek atau taksi atau transportasi online, dengan proporsi sebesar $42,2 \%$ (186 responden) dan diikuti dengan menggunakan kendaraan pribadi (penumpang) dan berjalan kaki, sebanyak 24,7\% (109 responden) dan 16,8\% (74 responden), secara berurutan.

Tabel 3 Tingkat Aksesibilitas Stasiun Secara Keseluruhan Berdasarkan Moda Terakhir

\begin{tabular}{lccccc}
\hline \multirow{2}{*}{ Moda Terakhir } & \multicolumn{4}{c}{ Tingkat Aksesibilitas Stasiun Secara } \\
\cline { 2 - 6 } & \multicolumn{4}{c}{ Keseluruhan $(\%)$} \\
\hline Berjalan Kaki $(\mathrm{n}=74)$ & & STB & TB & CB & SB \\
Kendaraan Pribadi (Pengemudi) $(\mathrm{n}=29)$ & 0,0 & 6,8 & 51,4 & 31,1 & 9,5 \\
Kendaraan Pribadi (Penumpang) $(\mathrm{n}=109)$ & 1,8 & 15,6 & 45,0 & 30,3 & 7,3 \\
Angkutan Umum (n = 43) & 0,0 & 2,3 & 44,2 & 44,2 & 9,3 \\
Ojek/Taksi/Transportasi Online $(\mathrm{n}=186)$ & 0,5 & 9,1 & 57,5 & 29,0 & 3,8 \\
\hline
\end{tabular}

Catatan: STB = Sangat Tidak Baik; TB = Tidak Baik; CB = Cukup Baik; B = Baik; SB = Sangat Baik

Tabel 4 Estimasi Regresi Ordinal Logit Model Kendaraan Pribadi (Penumpang)

Sebagai Moda Terakhir $(\mathrm{n}=109)$

\begin{tabular}{|c|c|c|c|c|c|c|}
\hline & & Estimate & Std. Error & Wald & $d f$ & Sig. \\
\hline \multicolumn{7}{|c|}{ Threshold: Tingkat Aksesibilitas Stasiun Secara Keseluruhan [Y] } \\
\hline Tidak Baik & $\mathrm{Y}=1$ & $-6,481$ & 1,265 & 26,250 & 1 & 0,000 \\
\hline Cukup Baik & $\mathrm{Y}=2$ & $-2,560$ & 1,077 & 5,651 & 1 & 0,017 \\
\hline \multicolumn{7}{|c|}{$\begin{array}{l}\text { Biaya yang dikeluarkan untuk mencapai stasiun dengan diantar (termasuk biaya parkir, jika ada) } \\
\text { menggunakan kendaraan pribadi menuju stasiun cukup terjangkau }\end{array}$} \\
\hline Tidak Setuju & $\mathrm{AC} 3=1$ & $-0,647$ & 0,918 & 0,496 & 1 & 0,481 \\
\hline Cukup Setuju & $\mathrm{AC} 3=2$ & $-1,063$ & 0,561 & 3,595 & 1 & 0,058 \\
\hline \multicolumn{7}{|c|}{$\begin{array}{l}\text { Terdapat jalur masuk kendaraan ke area stasiun yang terlihat jelas dan mudah diakses dari jaringan jalan } \\
\text { sekitar stasiun }\end{array}$} \\
\hline Tidak Setuju & $\mathrm{AC} 4=1$ & $-1,552$ & 0,681 & 5,189 & 1 & 0,023 \\
\hline Cukup Setuju & $\mathrm{AC} 4=2$ & $-0,124$ & 0,599 & 0,043 & 1 & 0,835 \\
\hline \multicolumn{7}{|c|}{ Terdapat papan informasi dan petunjuk arah untuk tempat turun penumpang (tempat drop off) yang jelas } \\
\hline Tidak Setuju & $\mathrm{AC} 5=1$ & $-2,198$ & 0,691 & 10,129 & 1 & 0,001 \\
\hline Cukup Setuju & $\mathrm{AC} 5=2$ & $-1,272$ & 0,755 & 2,841 & 1 & 0,092 \\
\hline \multicolumn{7}{|c|}{ Terdapat pencahayaan yang baik pada tempat turun penumpang (tempat drop off) } \\
\hline Tidak Setuju & $\mathrm{AC} 8=1$ & $-3,314$ & 0,733 & 20,460 & 1 & 0,000 \\
\hline Cukup Setuju & $\mathrm{AC} 8=2$ & $-1,590$ & 0,644 & 6,098 & 1 & 0,014 \\
\hline \multicolumn{7}{|c|}{ Tersesat dalam perjalanan menuju stasiun yang menyebabkan keterlambatan } \\
\hline & N3 & $-0,759$ & 0,357 & 4,507 & 1 & 0,034 \\
\hline \multicolumn{7}{|c|}{ Kecelakaan dalam perjalanan menuju stasiun } \\
\hline & N4 & 1,029 & 0,617 & 2,782 & 1 & 0,095 \\
\hline
\end{tabular}

Tabel 3 memperlihatkan proporsi penilaian terhadap tingkat aksesibilitas stasiun secara keseluruhan, yang dibagi berdasarkan moda terakhir dalam perjalanan menuju stasiun asal. Hampir setengah dari responden $(45,0 \%)$ dengan moda terakhir kendaraan pribadi (penumpang) memberikan penilaian 'Cukup Baik' terhadap tingkat aksesibilitas stasiun. Dalam proporsi penilaian responden dengan moda terakhir ojek, taksi, atau transportasi online, dapat dilihat bahwa lebih dari setengah responden menjawab 'Cukup Baik', yaitu sebanyak 57,5\%, dan diikuti dengan pilihan jawaban 'Baik' sebanyak 29,0\%. Untuk analisis 
lebih lanjut dalam model regresi ordinal logit, data yang digunakan adalah 2 dari 5 moda transportasi terakhir dalam satu kali perjalanan menuju stasiun asal. Data yang digunakan adalah data responden dengan moda terakhir ojek, taksi, atau transportasi online dan kendaraan pribadi (penumpang) sebagai 2 jenis moda terakhir dengan jumlah responden terbanyak.

\section{Estimasi Model Regresi Ordinal Logit}

Estimasi model regresi ordinal logit yang disajikan pada Tabel 4 menghasilkan 4 variabel berpengaruh, yaitu variabel dengan nilai signifikansi lebih kecil dari $\alpha$ yang digunakan, yaitu sebesar 0,05. Hal ini menyatakan bahwa atribut yang berpengaruh terhadap penilaian responden mengenai tingkat aksesibilitas stasiun adalah jalur masuk kendaraan ke area stasiun, papan informasi dan petunjuk arah tempat turun penumpang, dan pencahayaan tempat turun penumpang. Selain variabel atribut aksesibilitas stasiun, variabel frekuensi pengalaman negatif berupa tersesat dalam perjalanan menuju stasiun juga memengaruhi penilaian responden pada model kendaraan pribadi (penumpang) sebagai moda terakhir.

Tabel 5 Estimasi Regresi Ordinal Logit Model Ojek/Taksi/Transportasi Online

Sebagai Moda Terakhir $(\mathrm{n}=186)$

\begin{tabular}{|c|c|c|c|c|c|c|}
\hline & & Estimate & Std. Error & Wald & $d f$ & Sig. \\
\hline \multicolumn{7}{|c|}{ Threshold: Tingkat Aksesibilitas Stasiun Secara Keseluruhan [Y] } \\
\hline Tidak Baik & $\mathrm{Y}=1$ & $-8,426$ & 0,952 & 78,328 & 1 & 0,000 \\
\hline Cukup Baik & $\mathrm{Y}=2$ & $-3,326$ & 0,662 & 25,224 & 1 & 0,000 \\
\hline \multicolumn{7}{|c|}{ Jarak antara lokasi naik taksi/ojek/transportasi online dan stasiun cukup dekat } \\
\hline Tidak Setuju & $\mathrm{AE} 1=1$ & $-1,930$ & 0,666 & 8,385 & 1 & 0,004 \\
\hline Cukup Setuju & $\mathrm{AE} 1=2$ & $-1,133$ & 0,458 & 6,106 & 1 & 0,013 \\
\hline \multicolumn{7}{|c|}{ Waktu tempuh menggunakan taksi/ojek/transportasi online cukup pendek } \\
\hline Tidak Setuju & $\mathrm{AE} 3=1$ & $-1,569$ & 0,598 & 6,894 & 1 & 0,009 \\
\hline Cukup Setuju & $\mathrm{AE} 3=2$ & $-0,850$ & 0,450 & 3,573 & 1 & 0,059 \\
\hline \multicolumn{7}{|c|}{$\begin{array}{l}\text { Terdapat papan informasi dan petunjuk arah untuk tempat turun penumpang (tempat drop off) yang } \\
\text { jelas }\end{array}$} \\
\hline Tidak Setuju & AE6=1 & $-1,462$ & 0,469 & 9,737 & 1 & 0,002 \\
\hline Cukup Setuju & $\mathrm{AE} 6=2$ & $-0,524$ & 0,521 & 1,011 & 1 & 0,315 \\
\hline \multicolumn{7}{|c|}{ Tempat turun penumpang (tempat $d$ rop off) aman dan nyaman } \\
\hline Tidak Setuju & $\mathrm{AE} 8=1$ & $-2,230$ & 0,683 & 10,646 & 1 & 0,001 \\
\hline Cukup Setuju & $\mathrm{AE} 8=2$ & $-1,238$ & 0,647 & 3,664 & 1 & 0,056 \\
\hline \multicolumn{7}{|c|}{ Terdapat pencahayaan yang baik pada tempat turun penumpang (tempat drop off) } \\
\hline Tidak Setuju & $\mathrm{AE} 9=1$ & $-1,711$ & 0,539 & 10,092 & 1 & 0,001 \\
\hline Cukup Setuju & $\mathrm{AE} 9=2$ & $-0,779$ & 0,478 & 2,660 & 1 & 0,103 \\
\hline \multicolumn{7}{|c|}{$\begin{array}{l}\text { Kesulitan untuk masuk ke area/gedung stasiun yang menyebabkan keterlambatan atau menimbulkan } \\
\text { rasa tidak aman/nyaman }\end{array}$} \\
\hline & $\mathrm{N} 2$ & $-0,283$ & 0,156 & 3,289 & 1 & 0,070 \\
\hline
\end{tabular}

Estimasi model regresi ordinal logit kedua disajikan pada Tabel 5. Hasil estimasi model memiliki 5 variabel yang berpengaruh secara signifikan terhadap variabel terikat tanpa adanya variabel mengenai frekuensi pengalaman negatif. Atribut yang berpengaruh terhadap penilaian responden mengenai tingkat aksesibilitas stasiun adalah jarak, waktu 
tempuh, papan informasi dan petunjuk arah tempat turun penumpang, keamanan dan kenyamanan tempat turun penumpang, serta pencahayaan tempat turun penumpang.

\section{DISKUSI}

Pada penelitian ini, moda transportasi untuk mencapai stasiun didominasi oleh kendaraan pribadi atau penumpang dan ojek, taksi, atau transportasi online. Hal ini dapat terjadi karena wilayah Jabodetabek dan sekitarnya, yang menyediakan layanan KRL Commuter Line, masih banyak bergantung pada kendaraan pribadi dan ojek, taksi, atau transportasi online, yang cenderung lebih praktis untuk mencapai suatu tempat. Penelitian ini difokuskan hanya pada penilaian terhadap tingkat aksesibilitas secara keseluruhan dengan persepsi responden yang juga spesifik untuk setiap moda transportasi, sehingga dapat diketahui variabel-variabel yang berpengaruh secara signifikan terhadap penilaian tingkat aksesibilitas stasiun sebagai salah satu aspek yang memengaruhi tingkat kepuasan pengguna dalam perjalanan menggunakan kereta api.

Berdasarkan variabel atribut aksesibilitas yang cenderung sama pada kedua model, diperoleh kesamaan terkait fasilitas yang perlu dijadikan prioritas untuk ditingkatkan, yaitu papan informasi dan petunjuk arah untuk tempat turun penumpang, serta pencahayaan pada tempat turun penumpang di area stasiun. Hasil ini mendukung studi Allen (2018) yang menyatakan bahwa pencahayaan pada sistem angkutan umum merupakan efisiensi untuk meningkatkan keamanan wanita selama jam operasional angkutan umum. Kendaraan pribadi juga merupakan moda transportasi yang paling banyak digunakan dalam akses untuk mencapai stasiun pada penelitian yang dilakukan Kim et al. (2007), sedangkan dalam penelitian Givoni dan Rietveld (2007) dikemukakan bahwa akses untuk mencapai stasiun didominasi oleh moda transportasi berjalan kaki, sepeda, dan angkutan umum, karena relatif mudahnya akses ke stasiun termasuk lingkungan yang mendukung penggunaan 3 moda tersebut dalam mencapai stasiun, sehingga tidak perlu bergantung pada kendaraan pribadi.

Rendahnya kualitas stasiun dan akses menuju stasiun yang menurut persepsi pengguna dapat menyebabkan pengguna menghindari penggunaan kereta api. Aspek pengalaman negatif juga merupakan bagian penting yang memengaruhi memori responden terhadap pelayanan angkutan umum, dalam hal ini KRL Commuter Line. Pengalaman tentang suatu pelayanan cenderung memengaruhi pelayanan tersebut untuk digunakan selanjutnya sehingga harus dapat dipastikan pengalaman negatif yang dialami tidak terjadi lagi di masa mendatang.

\section{KESIMPULAN}

Hasil studi ini menunjukkan bahwa responden yang memiliki persepsi kurang baik pada jalur masuk kendaraan ke area stasiun, papan informasi dan petunjuk arah tempat turun 
penumpang, serta frekuensi pengalaman negatif berupa tersesat dalam perjalanan menuju stasiun, cenderung memberikan penilaian yang rendah terhadap tingkat aksesibilitas stasiun secara keseluruhan. Hal yang sama berlaku juga pada model untuk pengguna moda terakhir ojek, taksi, atau transportasi online, yaitu pada variabel waktu tempuh, papan informasi dan petunjuk arah tempat turun penumpang, keamanan dan kenyamanan tempat turun penumpang, serta pencahayaan tempat turun penumpang.

Temuan studi ini menujukkan bahwa fasilitas kelengkapan informasi dan infrastruktur jalur masuk ke stasiun sangat penting dalam meningkatkan aksesibilitas pengguna angkutan umum, khususnya perempuan. Hal ini dapat menjadi masukan terhadap operator angkutan umum untuk melakukan perbaikan dan penyempurnaan infrastruktur, seperti fasilitas trotoar dan papan penunjuk arah, khususnya di area stasiun KRL Commuter Line. Pembahasan mengenai rangkaian perjalanan pulang-pergi yang meliputi akses menuju stasiun dan akses meninggalkan stasiun (access and egress) akan mengakomodasi informasi yang lebih lengkap mengenai keseluruhan perjalanan menggunakan KRL Commuter Line.

\section{DAFTAR PUSTAKA}

Allen, H. 2018. Approaches for Gender Responsive Urban Mobility. Bonn: GiZ-SUTP.

Black. J. 1981. Urban Transport Planning. London: Croom Helm.

Givoni, M. dan Rietveld, P. 2007. The Access Journey to The Railway Station and Its Role in Passengers' Satisfaction with Rail Travel. Transport Policy, 14 (5): 357-365.

Hikam, H. 2019. Akses Transportasi Umum di Jakarta Harus Diperbanyak. (Online), (https://finance.detik.com/berita-ekonomi-bisnis/d-4644212/akses-transportasi-umumdi-jakarta-harus-diperbanyak, diakses 8 Maret 2020).

Intari, D.E., Suryani, I., dan Septya, I. 2017. Evaluasi Kinerja Pelayanan Stasiun Kereta Api Bogor di Kota Bogor, Jawa Barat. Jurnal Fondasi, 6 (1): 11-22.

Israel, G.D. 2009. Determining Sample Size. Agricultural Education and Communication Department, Florida Cooperative Extension Service, Institute of Food and Agricultural Sciences. Gainesville, FL: University of Florida.

Lusiani, M. dan Chandra, S. 2018. Optimasi Jumlah Kedatangan KRL Commuter Line untuk Mengatasi Penumpukan Penumpang Jalur Bekasi-Jakarta Kota Menggunakan Simulasi Promodel. JIEMS (Journal of Industrial Engineering and Management Systems), 11 (1): 32-38.

Maffi, S., Malgieri, P., dan Di Bartolo, C. 2015. CIVITAS Policy Note: Gender Equality and Mobility: Mind the Gap!. Torino.

Saleh, T. 2019. Tahun Ini, KRL Commuter Line Bidik 1,2 Penumpang/Hari. (Online), (https://www.cnbcindonesia.com/news/20190310144514-4-59728/tahun-ini-krl-com muter-line-bidik-12-penumpang-hari, diakses 19 November 2019).

Sukwadi, R. dan Teofilus, G. 2015. Behavioral Intention Penumpang KRL Commuter Line Jabodetabek. Jurnal Teknik Industri, 10 (2): 71-76. 
Tamin, O.Z. 2000. Perencanaan \& Pemodelan Transportasi. Bandung: Penerbit Institut Teknologi Bandung.

Van Wee, B. dan Geurs, K. 2011. Discussing Equity and Social Exclusion in Accessibility Evaluations. European Journal of Transport and Infrastructure Research, 11 (4): 350367. 